\title{
Control Strategy for Bidirectional HBCS Converter for Supercapacitor Applications
}

\author{
Jorge Garcia*, Fabio Giulii Capponił, Gabriele Boroccił, Pablo Garcia* \\ Dept. of Electrical Engineering, University of Oviedo \\ LEMUR research group, Campus de Viesques \\ Gijon, Spain \\ garciajorge@uniovi.es \\ Department of Electrical Engineering, University of Roma \\ "La Sapienza" \\ Via Eudossiana, 18 - 00184 Roma, Italy \\ fabio.giuliicapponi@uniroma1.it
}

\begin{abstract}
This paper proposes the basic average model and the design of the control system for the Half Bridge Current Source (HBCS) Bidirectional DC to DC Converter. This converter is intended to interface a High Voltage DC link and a Low Voltage DC Storage Device in transportation applications.

Firstly, the basics of the converter operation, high-level control and the simplified modeling are presented. Then, a cascaded control approach for the whole system is discussed and validated through simulations.
\end{abstract}

Keywords-Bidirectional Converter; Synchronous Rectification, Supercapacitors, Bidirectinoal current control

\section{INTRODUCTION}

Supercapacitors (SCs) are the best solution for high peak power storage/delivery in power systems with high transient power flow requirements, as for instance electric vehicles. The primary storage system is generally given by batteries or fuel cells (in the rest of the paper a battery storage will be considered, just for sake of simplicity, with no loss of generality in the conclusions). Batteries are sized to provide the energy storage capability, but since they have poor dynamics compared with the necessities of the full system, they will not - in general - be able to provide the short-time power peaks required by the load [1]. In order to solve this lack of high peak power capabilities, additional power storage systems, such as supercapacitors, should be used.

Whenever considering the adoption of an energy source (batteries) and a power source (SCs), the configuration that allow to achieve the best performances and the highest efficiency must be selected. Both the series configuration [1]-[2] or cascaded configuration [3]-[4] imply that the primary source energy must be processed twice, which yields to a decrease in efficiency. Thus, the parallel configuration [5]-[7], as depicted in Figure 1, is considered to be the most suitable on in terms of efficiency and design versatility. [8]-[9].

In this configuration, the SCs are connected in parallel to the battery stack by means of a DC to DC bidirectional converter. This converter is intended to control the power flow between the battery, the SC and the output load. In the most common transportation applications, the battery stack voltage is above $300 \mathrm{~V}_{\mathrm{DC}}$, whereas the $\mathrm{SC}$ assembly voltage is significantly lower, in the order of $50 \mathrm{~V}_{\mathrm{DC}}$ or even lower.
With such a high mismatch in the voltage levels between the battery (the higher voltage DC link) and the SCs (the lower voltage DC link), the use of a transformer in the DC to DC topology is justified [10]-[21]. Among the different topologies that are suitable for this application, the Half Bridge Current Source (HBCS) converter, depicted in Figure 2, has been proposed as an adequate bidirectional DC to DC converter topology [18]-[21]. This topology outstands as the one of the best options in terms of size and efficiency versus the most usual isolated bidirectThe control ional topologies considered, i.e. the active-clamp double-Flyback converter, the forward current-source converter and the Push-Pull current-source converter [21].

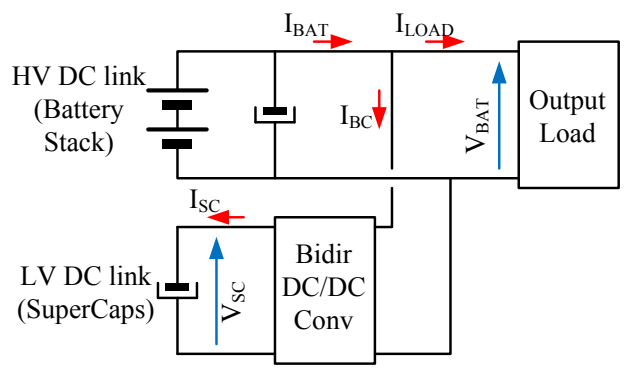

Figure 1. Parallel configuration for interfacing Supercapacitors with primary energy source (Battery Stack)

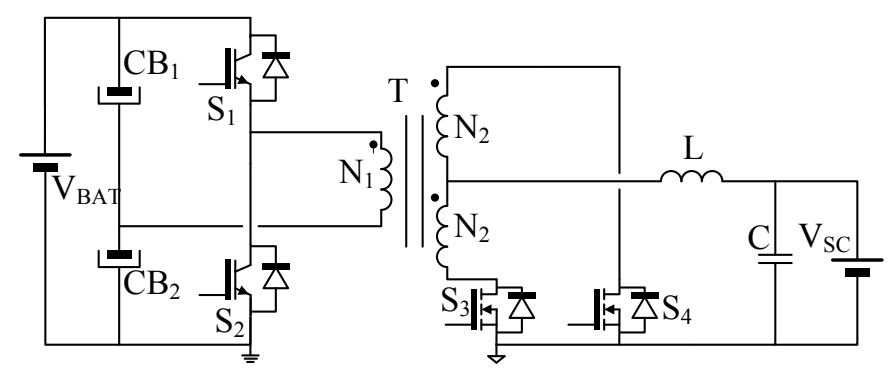

Figure 2. Layout of HBSC bidirectional converter

In this work, the control scheme of the HBCS converter within the full system is studied and designed. Firstly, an average model of the HBCS converter is proposed and defined. This model is used as a tool for the proper design of the control strategy of the full interfacing system. A control 
design scheme based on a cascaded control loop approach is then presented as an option for the full system control. It is demonstrated how this control strategy is capable of managing the power flow between the batteries and the SCs on one side, and the load on the other side.

The paper is organized as follows. Section II provides an overview of working principles of the HBSC converter, mainly concentrating on the switching operation and the expression of the static gain. Section III provides an overview of the control system structure. After that, Section IV shows the system modelling. Section V deals with the closed loop design, and after that, Section VI shows simulated demonstration of the system performance. Finally, Section VII states conclusions and future developments of the work.

\section{THE HBCS CONVERTER}

The switching scheme considered here for the HBCS converter is a synchronous rectification strategy with phaseshifting. With the conventional voltages and currents considered in Figure 3, a positive current $\mathrm{I}_{\mathrm{BC}}$ means that the converter is operating in SCs charging mode, which corresponds also to a positive $\mathrm{I}_{\mathrm{SC}}$ current. When the power flow reverses (SCs in discharging mode), both $\mathrm{I}_{\mathrm{BC}}$ and $\mathrm{I}_{\mathrm{SC}}$ will also reverse sign.

Switches $S_{1}$ and $S_{2}$ operate with the same duty ratio, but with a phase-shift of $180^{\circ}$. This provides symmetrical current and voltage waveforms that simplify significantly the study of the power converter, and equalizes the current and voltage efforts among the switches [19]-[21]. Furthermore, in order to allow the net current flow in either direction, a synchronous switching scheme between the switches of the primary and the secondary side are considered and implemented. Provided that switches $\mathrm{S}_{1}$ and $\mathrm{S}_{4}$ (and also correspondingly $\mathrm{S}_{2}$ and $\mathrm{S}_{3}$ ) operate in synchronous rectification mode, then the current through the inductor filter (and hence the current through the SC) can flow in both directions. This feature can be seen in the waveforms presented in Figure 4.

A brief discussion is actually required for the current $\mathrm{I}_{\mathrm{BC}}$. From the analysis in Figure 4, that assumes ideal components and specifically an ideal voltage source for $\mathrm{V}_{\mathrm{BAT}}$, it seems that this current is highly discontinuous. However, when a real voltage source is considered (as in the case of batteries), and depending on the value of the equivalent series impedance of the Thevenin circuit as shown at Figure 5, the AC component of the current will be given by the capacitors $\mathrm{CB}_{1}$ and $\mathrm{CB}_{2}$, while the current $\mathrm{I}_{\mathrm{BC}}$ actually absorbed from or delivered to the high voltage DC link is just the continuous component. This issue is depicted in Figure 7.

According to [13], the relationship between the high voltage $\mathrm{DC}$ link, $\mathrm{V}_{\mathrm{BAT}}$ and the average voltage in a switching period at the midpoint of the secondary winding, $\mathrm{V}_{\mathrm{O}}$, for ideal components, can be calculated as follows. This assumption of ideal components is taken into account for the basic analysis of the converter; however it must be questioned when designing the control scheme, as it will have important effects in the final system operation.

Considering the waveforms at Figure 4, the expression of $\mathrm{V}_{\mathrm{O}}(\mathrm{t})$ as a function of the primary side voltage, $\mathrm{V}_{\mathrm{PRI}}(\mathrm{t})$ is, :

$$
\mathrm{V}_{\mathrm{O}}(\mathrm{t})=\left|\mathrm{V}_{\mathrm{PRI}}(\mathrm{t})\right| \cdot \frac{\mathrm{N}_{2}}{\mathrm{~N}_{1}}
$$

where $\left|\mathrm{V}_{\text {PRI }}(\mathrm{t})\right|$ represents the rectified voltage waveform of the primary winding. Also from Figure 4, this rectified value can be expressed as:

$$
\left|V_{\text {PRI }}(t)\right|=\frac{V_{B A T}}{2} \cdot f(t)
$$

where $f(t)$ is

$$
f(t)= \begin{cases}1 & (0 \leq t<D T) \text { or }\left(\frac{T}{2} \leq t<\frac{T}{2}+D T\right) \\ 0 & \left(D T \leq t<\frac{T}{2}\right) \text { or }\left(\frac{T}{2}+D T \leq t<T\right)\end{cases}
$$

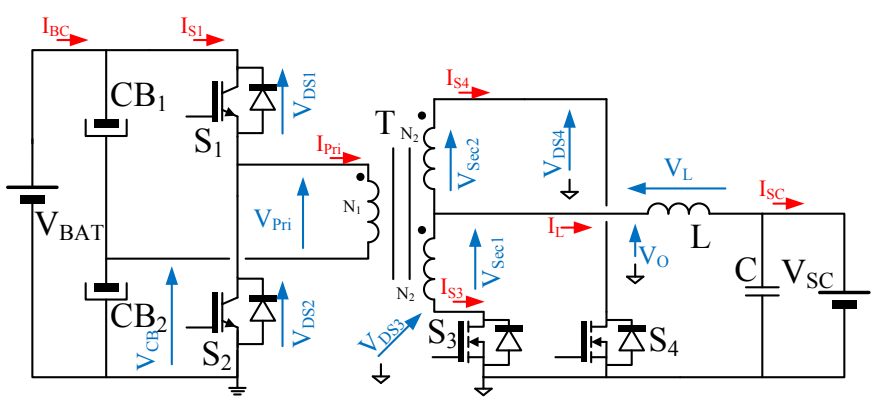

Figure 3. Conventional voltage and currents considered for the analysis of the HBSC bidirectional converter
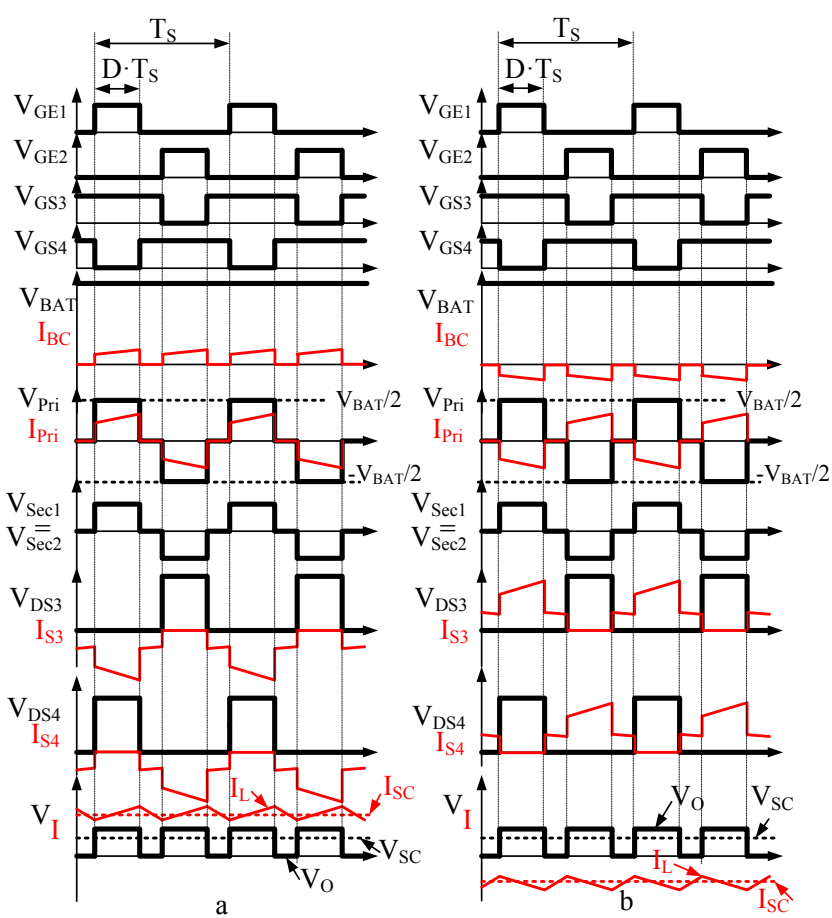

Figure 4. Main voltage (black) and current (red) waveforms of the HBSC for SCs charging (a) and discharging (b) operation mode (references of Figure 3)

Thus, from (1) and (2), the expression of $\mathrm{V}_{\mathrm{O}}(\mathrm{t})$ is:

$$
\mathrm{V}_{\mathrm{O}}(\mathrm{t})=\mathrm{f}(\mathrm{t}) \cdot \frac{\mathrm{V}_{\mathrm{BAT}}}{2} \cdot \frac{\mathrm{N}_{2}}{\mathrm{~N}_{1}}
$$


Considering the mesh formed by the filter inductor, the output voltage and the midpoint of the transformer, then the output voltage at the SC can be expressed as

$$
V_{S C}(t)=V_{O}(t)-V_{L}(t)=f(t) \cdot \frac{V_{B A T}}{2} \cdot \frac{N_{2}}{N_{1}}-V_{L}(t)
$$

Representing with bold letters the average value of a given instant parameter in a switching period, T, of a given instant parameter, then the following expression is obtained from (5):

$$
\mathbf{V}_{\text {SC }}=2 \cdot \mathbf{D} \cdot \frac{\mathrm{V}_{\mathrm{BAT}}}{2} \cdot \frac{\mathrm{N}_{2}}{\mathrm{~N}_{1}}-\mathbf{V}_{\mathbf{L}}
$$

Equation (6) takes into account that the average value of $f(t)$ in eq. (3) equals $2 \cdot \mathbf{D}$, which can be easily demonstrated.

Finally, the static gain of the converter, $\mathrm{G}_{\mathrm{HBCS}}$, can be calculated considering that in steady state the average value of inductor voltage equals to zero:

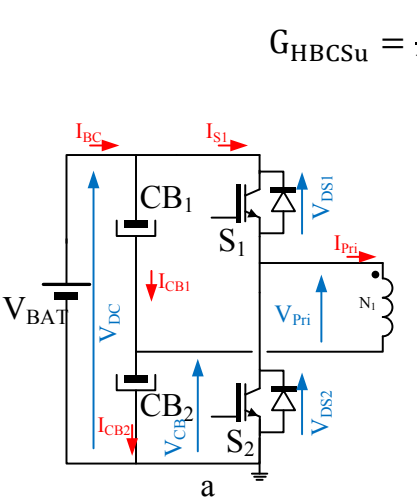

$$
\frac{\mathrm{V}_{\mathrm{SC}}}{\mathrm{V}_{\mathrm{BAT}}}=\mathrm{D} \cdot \frac{\mathrm{N}_{2}}{\mathrm{~N}_{1}}
$$

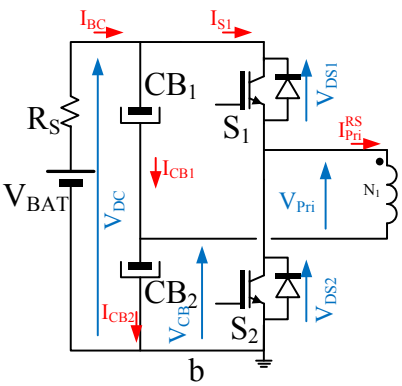

Figure 5. a) HVDC link side of the converter, considering a) the battery as an ideal voltage source, and b) the battery as a Thevenin equivalent formed by a voltge source and a series resistor, $\mathrm{R}_{\mathrm{S}}$

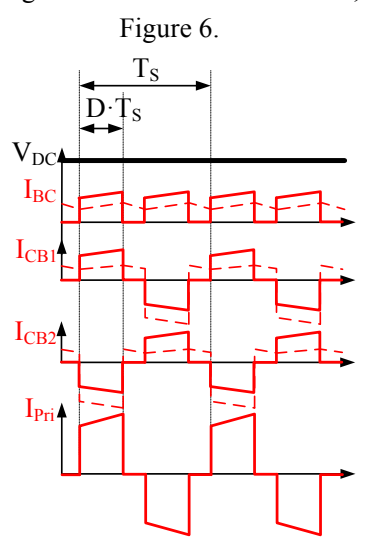

Figure 7. HVDC link current $\left(\mathrm{I}_{\mathrm{BC}}\right)$, half bridge capacitor currents $\left(\mathrm{I}_{\mathrm{CB} 1}\right.$ and $\mathrm{I}_{\mathrm{CB} 2}$ ) and primary current, $\mathrm{I}_{\mathrm{Pri}}$, considering both ideal input voltage source (red lines) and Thevenin equivalen circuit input (red dashed lines).

\section{CONTROL StRATEgy FOR THE System POWER Flow}

Figure 8 shows the control strategy for the intended application depicted in Figure 1. A High-Level Control (HLC) system is monitoring the battery parameters as well as the current requirements from the output load. Based on these measurements, along with the desired operation scheme, the HLC system provides a reference value for the HV side current of the converter, represented by $\mathrm{I}_{\mathrm{BC}} *$. The operation of the HLC system is out of the scope of this paper, and it should take into account the storage system technologies and dynamics, the intended operation of the full system, and the requirements of the output load. Among other issues, it would fully define the charging/discharging characteristics of both the SCs and the batteries, the power sharing in transients and steady state, the thermal management, etc. The present work, instead, deals with the implementation of the Converter Control (CC) system that considers the $\mathrm{I}_{\mathrm{BC}} *$ reference as the input parameter, as provided by the HLC system.

The Converter Control System takes this $\mathrm{I}_{\mathrm{BC}} *$ value as the reference for the closed-loop control system, and based on the $\mathrm{I}_{\mathrm{BC}}$ sensed value, provides an error to the control loop that finally states a Control Action, CA. This Control Action is passed to the PWM block, which generates the appropriate PWM signals for the four switches of the converter.

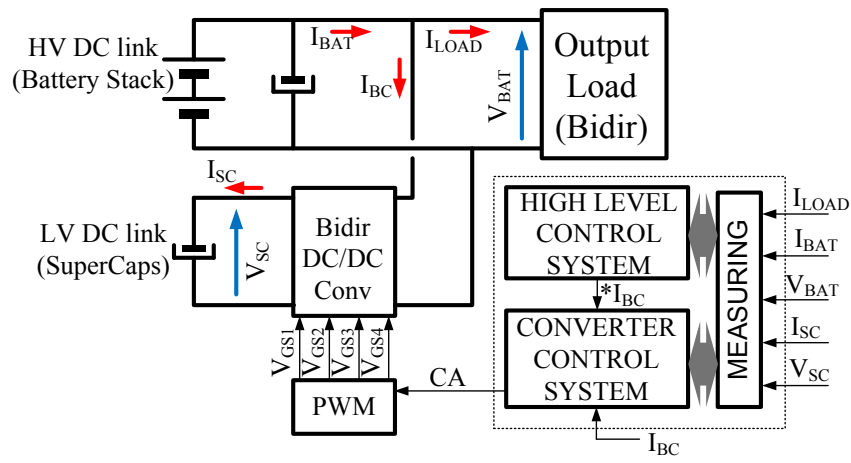

Figure 8. Control Strategy for the HBCS converter

The control scheme is actually implemented through an approach based on cascaded control loops, as depicted in Figure 9. The main control parameter is the HVDC link current, $\mathrm{I}_{\mathrm{BC}}$, being a critical parameter of the system. A tight control of this current will allow for a proper operation of the full system, as it will cancel any eventual mismatch between the battery current and the load current.

On the other hand, some parameter at the SCs must also be controlled in order to avoid dangerous voltages or currents at the SCs. As it can be seen, the converter operates under an inductor current $\left(\mathrm{I}_{\mathrm{L}}\right)$ control. Provided that the output filter capacitor, $\mathrm{C}$, has an adequate value, it can be assumed that the average value of the inductor current, $\mathrm{I}_{\mathrm{L}}$, equals the average $\mathrm{SC}$ current, $\mathrm{I}_{\mathrm{SC}}$.

$$
\mathbf{I}_{\mathbf{L}}=\mathbf{I}_{\mathbf{S C}}
$$

Thus in order to define both the external and internal regulators, a full model of the behaviour of the system is needed, in order to settle the $i_{L}$-to- $i_{B C}$ current relationships, $\mathrm{G}_{\mathrm{I}}(\mathrm{s})$.

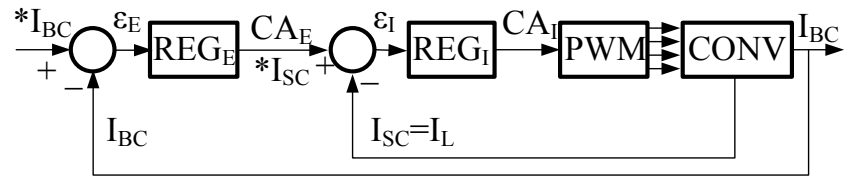


Figure 9. Cascaded loop approach for control strategy.

The cascaded control strategy allows for the full decoupling of the control variables $\mathrm{I}_{\mathrm{L}}$ (i.e. $\mathrm{I}_{\mathrm{SC}}$ ) and $\mathrm{I}_{\mathrm{BC}}$. The relationship between the currents is a function mainly of the duty ratio, D. It can be demonstrated, although it is out of the scope of this work, that this relationship is not linear, mainly due parasitic components of the reactive elements of the circuit. However, in this work the most simple relationship between these $I_{L}$ and $I_{B C}$ currents will be considered, in order to simplify the followed design procedure.

Thus, the cascaded scheme enables for a full control of the current at the HV side, which will finally regulate the power flow between the two sources and the load. This operation of the HV side current will be independent of the SC subsystem, as long as the operating constraints are not trespassed.

\section{MODEL OF THE CONVERTER}

Having discussed the switching strategy and once the control scheme is defined, the next step is to establish a model intended to determine the behaviour of the converter. This model will be necessary in order to design the control system.

From equations (7) and (8), and considering ideal components and $100 \%$ efficiency, the relationship between the $\mathrm{I}_{\mathrm{BC}}$ and $\mathrm{I}_{\mathrm{SC}}$ currents can be easily calculated:

$$
\begin{gathered}
\mathbf{P}_{\mathrm{BAT}}=\mathrm{V}_{\mathrm{BAT}} \cdot \mathbf{I}_{\mathrm{BC}}=\mathbf{V}_{\mathbf{S C}} \cdot \mathbf{I}_{\mathbf{S C}}=\mathbf{P}_{\mathbf{S C}} \\
\mathbf{I}_{\mathrm{BC}}=\mathbf{D} \cdot \frac{\mathrm{N}_{2}}{\mathrm{~N}_{1}} \cdot \mathbf{I}_{\mathbf{L}}=\mathbf{D} \cdot \frac{\mathrm{N}_{2}}{\mathrm{~N}_{1}} \cdot \mathbf{I}_{\mathbf{S C}}
\end{gathered}
$$

The simplest average model for the power stage fulfilling these equations is depicted in Figure 10. In such a model, the switches and the transformer have been substituted by the two dependant sources, which are a function of both the duty ratio and the turns ratio of the transformer. After that, the LC filter and the load are considered.

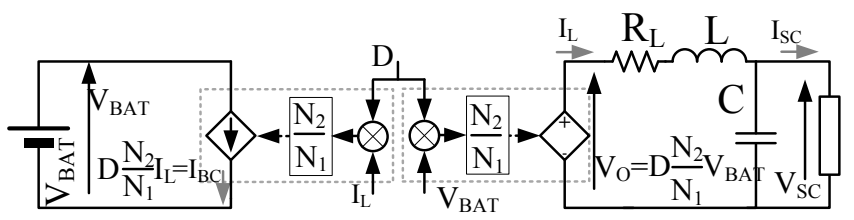

Figure 10. Model based on ideal components

\section{CONTROL LOOP DESIGN}

Representing in standard Capital letters the steady state value of the variables, and in italic letters with a symbol ${ }^{\wedge}$ the small-signal values, equation, then a generic averaged signal, $\mathbf{X}$, can be expressed as:

$$
\mathbf{X}=\mathrm{X}+\hat{x}
$$

After linearizing and perturbing (8), it is clear that:

$$
\widehat{\iota_{L}}=\widehat{\iota_{S C}}
$$

The inner regulator selected is a PI regulator. The pole cancellation design method has been used for tuning the internal PI regulator. Thus, the output of the PI regulator, is the control action of the inner loop, that has the physical meaning of the inductor voltage, $\widehat{v_{L}}$, as it is shown in Figure 11. However, the control signal that can be sent to the system is the duty ratio, $\mathbf{D}$, as the sum of the steady-state value, $\mathrm{D}$, and the small-signal value, $\hat{d}$. By rearranging equation (6), the expression of the duty ratio can be calculated as:

$$
\mathbf{D}=\frac{\mathrm{N}_{1}}{\mathrm{~N}_{2}} \cdot \frac{\mathrm{V}_{\mathrm{SC}}+\mathrm{V}_{\mathbf{L}}}{\mathrm{V}_{\mathrm{BAT}}}
$$

The small-signal relationship between the inductor voltage and the duty ratio, $\mathrm{G}_{\mathrm{dvL}}$ can be derived from (13) considering (11), which yields to:

$$
\hat{d}=\frac{\mathrm{N}_{1}}{\mathrm{~N}_{2}} \cdot \frac{\widehat{v_{S C}}+\widehat{v_{L}}}{\mathrm{~V}_{\mathrm{BAT}}}
$$

And hence,

$$
G_{d v_{L}}=\left.\frac{\widehat{d}}{\widehat{v}_{L}}\right|_{\widehat{v_{S C}}=0}=\frac{\mathrm{N}_{1}}{\mathrm{~N}_{2}} \cdot \frac{1}{\mathrm{~V}_{\mathrm{BAT}}}
$$

On the other hand, from (7), the value of the steady state of the duty ratio, $\mathrm{D}$, can be expressed as:

$$
\mathrm{D}=\frac{\mathrm{V}_{\mathrm{SC}}}{\mathrm{V}_{\mathrm{BAT}}} \cdot \frac{\mathrm{N}_{1}}{\mathrm{~N}_{2}}
$$

Equations (14) and (16) are included in Figure 11 in order to calculate the final value of $\mathbf{D}$ that is sent to the converter. As it can be seen, the inner regulator is then designed considering only the dynamics of the filter inductor (relationship between $\hat{\imath}_{L}$ and $\hat{u}_{L}$ ), which simplifies the tuning of the controller.

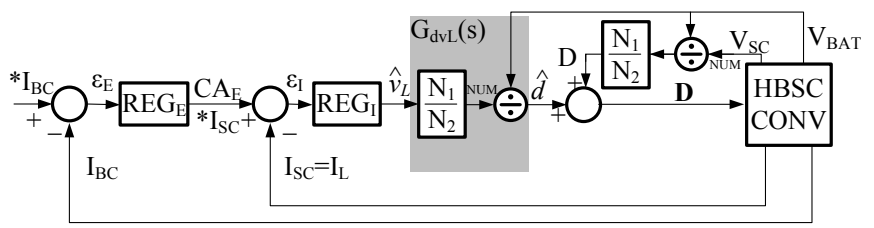

Figure 11. Duty ratio derivation in the proposed control scheme The shadowed area depicts the transfer function between the small-signal values of the duty ratio and the inductor voltage.

The outer regulator is also a PI controller, tuned considering that the relationship between the inductor current, $\mathrm{I}_{\mathrm{L}}$, and the HV DC link current, $\mathrm{I}_{\mathrm{BC}}$, can be considered as a constant, provided that the switches and the transformer can be assumed as ideal components. From the stated model, this relationship can be expressed by:

$$
\mathrm{G}_{\mathrm{HBCSi}}=\frac{\mathrm{I}_{\mathbf{L}}}{\mathrm{I}_{\mathrm{BC}}}=\frac{\mathrm{N}_{1}}{\mathrm{~N}_{2}} \cdot \frac{1}{\mathrm{D}}
$$

Following a similar procedure, it can be demonstrated how to tune this regulator, only the dynamics of the inner loop control (given by the tuning of the inner regulator) need to be considered. The design procedure to tune the regulator is again the pole cancellation.

\section{DEMONSTRATION OF THE CONTROL STRATEGY}

The proposed control strategy has been applied to an existing HBCS prototype, whose main characteristics are resumed in Table I [19]-[21]. 
Figure 1 shows a simulation of the HBCS power stage with the parameters from Table I, with the proposed control scheme. The plots presented are the results obtained from step changes in the current reference, $\mathrm{I}_{\mathrm{BC}}{ }^{*}$, and which include both charging and discharging mode (positive and negative value for this reference).

Table I. Characteristics of HBSC design

\begin{tabular}{|c|c|}
\hline \multicolumn{2}{|c|}{ HBSC Prototype Design } \\
\hline Parameter & $25-45 \mathrm{~V}$ \\
\hline SCs Voltage, $\mathrm{V}_{\mathrm{SC}}$ & $350 \mathrm{~V}$ \\
\hline HV DC link Voltage, $\mathrm{V}_{\mathrm{BAT}}$ & $20 \mathrm{kHz}$. \\
\hline Switching Frequency, $\mathrm{f}_{\mathrm{S}}$ & $0.25-0.45$ \\
\hline Duty cycle, $\mathrm{D}$ & $\pm 65 \mathrm{~A}$ \\
\hline Max SC current, $\mathrm{I}_{\mathrm{SC}}$ & $\pm 1.6(\mathrm{D}=0.25)$ \\
\hline Max. power, $\mathrm{P}_{\mathrm{O}}$ & $\pm 3 \mathrm{~kW}(\mathrm{D}=0.45)$ \\
\hline Transformer Ratio, $\mathrm{N}_{1}: \mathrm{N}_{2}$ & $3.5: 1$ \\
\hline Filter inductor, $\mathrm{L}$ & $27 \mu \mathrm{H}$ \\
\hline Filter inductor series resistor, $\mathrm{R}_{\mathrm{L}}$ & $4 \mathrm{~m} \Omega$ \\
\hline Output capacitor, $\mathrm{C}$ & $4.7 \mathrm{mF}$ \\
\hline
\end{tabular}

The bandwidth for the inner control loop is $2 \mathrm{kHz}$, a decade below the switching frequency of $20 \mathrm{kHz}$, in order to allow for a sufficient margin for anti-aliasing filtering. On the other hand, the bandwidth for the outer loop is $500 \mathrm{~Hz}$. This bandwidth has been chosen lower than the inner loop bandwidth, but it has been pushed as high as possible in order to provide the system with the fastest achievable dynamic response.

Table II provides the numerical parameters of the controllers.

Table II. Parameters of controllers

\begin{tabular}{|c|c|c|}
\hline \multicolumn{3}{|c|}{ HBSC Control Parameters } \\
\hline Parameter & Symbol & Value \\
\hline Bandwidth of internal controller & $B \mathrm{Wi}$ & $2 \mathrm{kHz}$ \\
\hline Type of Controller & $P I$ & - \\
\hline Time constant & $T_{I i}$ & $6.75 \mathrm{~ms}$ \\
\hline Proportional constant & $K_{P i}$ & 0.34 \\
\hline Bandwidth of external controller & $B W e$ & $500 \mathrm{~Hz}$ \\
\hline Type of Controller & $P I$ & - \\
\hline Time constant & $T_{I e}$ & $79.6 \mu \mathrm{s}$ \\
\hline Proportional constant & $K_{P e}$ & 0.25 \\
\hline
\end{tabular}

It must be noticed that in addition to the stated cascaded loop control, also a current derating control and an anti windup control have been included. The current derating control avoids the selection of a current reference greater that the absolute maximum ratings stated in Table I. Since the maximum power than the converter can process depends on the state of charge of the SCs, it follows that the maximum current allowed for the HV DC link has a linear behaviour proportional to the SCs voltage. In Figure 1, an example can be seen in which the current reference, $\mathrm{I}_{\mathrm{BC}}{ }^{*}$, is higher than the maximum allowable current and therefore the current derating control acts in order to limit the effective reference, $\mathrm{I}_{\mathrm{BC} \_ \text {derating }} *$.

The anti-wind-up control, instead, is placed in order to avoid that the duty ratio exceeds $45 \%$. Still in Figure 1, it can be seen how approximately at 0.26 seconds of the simulation, the control action that determines the duty ratio, CA (D), gets to $45 \%$, and then the current through the inductor starts to decrease due the anti wind-up control implemented. It can be seen how the current reference after the anti wind-up control, $\mathrm{I}_{\mathrm{BC} \_\mathrm{AWU}}{ }^{*}$, is from this point different from the current derating reference, $\mathrm{I}_{\mathrm{BC} \text { derating }}{ }^{*}$. However, the actual value of the current, $\mathrm{I}_{\mathrm{BC}}$, follows this reference any time.

Also, the references and actual values for the inductor current, $\mathrm{I}_{\mathrm{L}}{ }^{*}$ and $\mathrm{I}_{\mathrm{L}}$, respectively, and the $\mathrm{SC}$ voltage, $\mathrm{V}_{\mathrm{SC}}$, are presented in Figure 1.
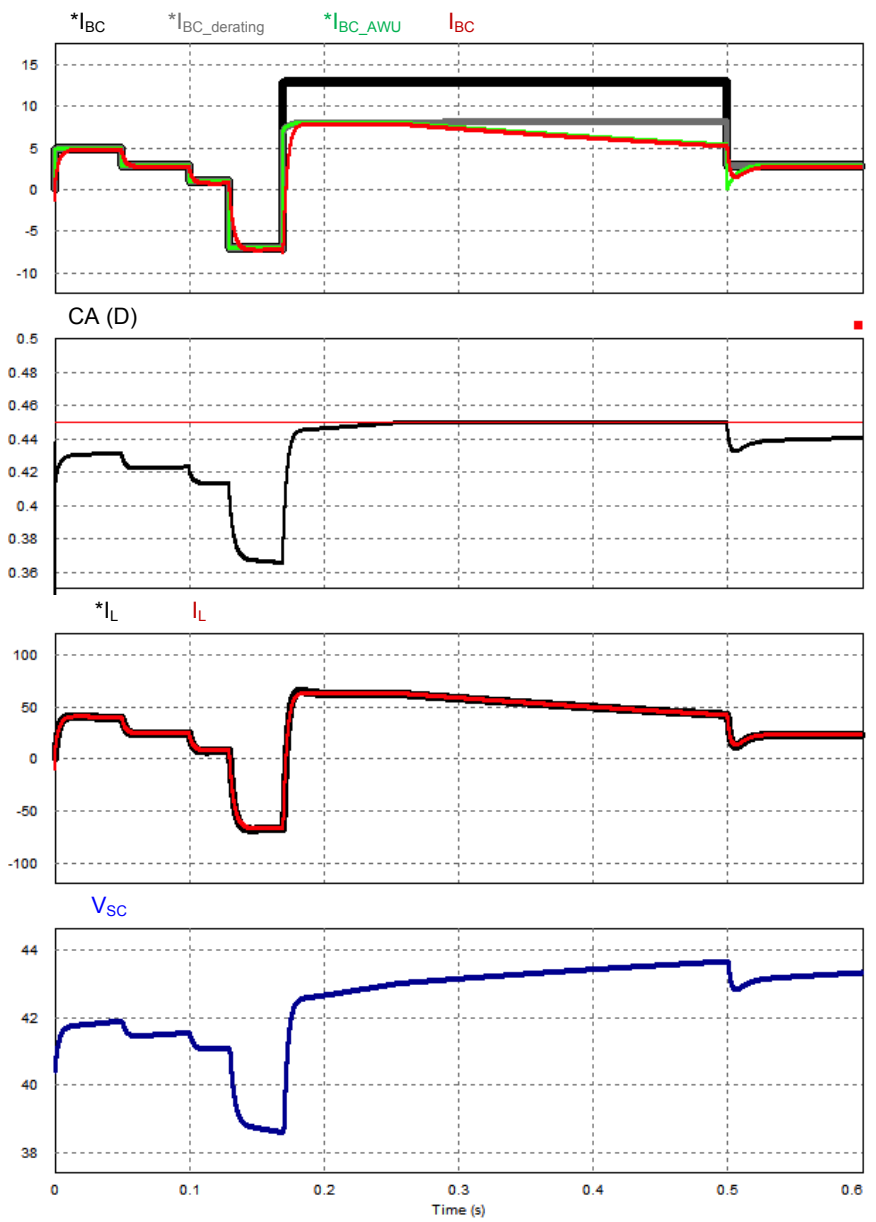

Figure 1. Demonstration of control scheme by simulations. $1^{\text {st }}$ plate: $I_{B C}$ current reference before (black, $I_{B C} *$ ) and after (grey. $\left.\mathrm{I}_{\mathrm{BCderating}}{ }^{*}\right)$ the current derating control, as well as reference afer anti wind-up control (green, $\mathrm{I}_{\mathrm{BC} \_\mathrm{AwU}}{ }^{*}$ ) and actual value (red, $\mathrm{I}_{\mathrm{BC}}$ ). $2^{\text {nd }}$ plate: Control action (Duty Ratio for the switches).

$3^{\text {rd }}$ plate: $\mathrm{I}_{\mathrm{L}}$ reference (grey, $\mathrm{I}_{\mathrm{L}}{ }^{*}$ ) and actual (red, $\mathrm{I}_{\mathrm{L}}$ ) inductor current values.

$4^{\text {th }}$ plate: Supercapacitors voltage, $\mathrm{V}_{\mathrm{SC}}$.

\section{CONCLUSIONS AND FUTURE DEVELOPMENTS}

The cascaded current control approach has been proposed, studied and validated for the HBCS bidirectional converter in supercapacitor applications. The design and tuning of the controllers has been carried out avoiding the use of complex averaged models of the full converter. Instead, it has been 
shown how a simple model of both the inductor filter and the $\mathrm{I}_{\mathrm{L}} / \mathrm{I}_{\mathrm{BC}}$ relationship is enough to achieve a good performance of the full system control. The reference of the HV DC link current, $\mathrm{I}_{\mathrm{BC}}$, can be determined by an external High Level Control system, thus providing a high versatility in the final system performance.

Future developments include the experimental validation of the control scheme, the inclusion of parasitic elements in the models, as well as a full design and tuning of the controllers for the proper operation of the converter upon different operating conditions.

\section{ACKNOWLEDGMENTS}

This work has been partially funded by the Campus of International Excellence (CEI) of the University of Oviedo, Spain, in the framework of Mobility Grants for Academics in 2013, partially funded by the Gijon City Hall, by resolution of BOPA 156, 6-VII2013.

\section{REFERENCES}

[1]. A. Di Napoli, F. Caricchi, F. Crescimbini, "Ultracapacitor based bidirectional DC-DC converter prototype for recovery of the braking energy in EV motor drives", 6th European Conf. on Power Electronics and Applications (EPE'95), Sevilla (Spain), September 1995.

[2]. P. Mestre, S. Astier, "Application of supercapacitors and influence of the drive control strategies on the performances of on electric vehicle", 15th Electric Vehicle Symposium (EVS-15), Bruxelles (Belgium), October 1998.

[3]. G.P. Barra, P.A. Genova, P. Morhet, G.P. Brusaglino, P. Rena, "Supercapacitors for EV, results, trends and industrial perspectives", 13th Electric Vehicle Symposium (EVS-13), Osaka (Japan), October 1996.

[4]. J. Takehara, K. Miyaoka, T. Fukuda, "EV Mini-Van Featuring Series Conjunction of Ultracapacitors and Batteries for Load Leveling of its Batteries", 15th Electric Vehicle Symposium (EVS-15), Bruxelles (Belgium), October 1998.

[5]. M. Schmid, "Electric Double-Layer Capacitor in a Hybrid Vehicle - Basic Considerations and Simulation Results", 13th Electric Vehicle Symposium (EVS-13), Osaka (Japan), October 1996.

[6]. R.D. King, J. Schwartz, M. Cardinal, L. Solasoo Garrigan, "Development and system test of high efficiency ultracapacitor/battery electronic interface", 15th Electric Vehicle Symposium (EVS-15), Bruxelles (Belgium), October 1998.

[7]. F. Caricchi, F. Crescimbini, A. Di Napoli, F. Giulii Capponi, L. Solero, 'Multiple input DC-DC power converter for power flow management in hybrid vehicles', 37th IEEE Industry Applications Society Annual Meeting (IAS'02), October 13-17, 2002, Pittsburgh, PA, USA, pp. 1578-1585.

[8]. A. Di Napoli, F. Giulii Capponi, L. Solero, "Power Converter Arrangements with Ultracapacitor Tank for Battery Load Leveling in EV Motor Drives" 8th European Conf. on Power Electronics and Applications (EPE'99), Lausanne (Switzerland), 7-9 September 1999.

[9]. F. Brucchi, G. Lo Bianco, P. Salvati, F. Giulii Capponi, L. Solero "Employment of Ultra-capacitors for Power Levelling Requirements in EV: a State of the Art" Proc. of 32nd
International Symposium on Automotive Technology and Automation (ISATA'99), Vienna (Austria), 14-18 June 1999.

[10]. Sangtaek Han; Divan, D., "Bi-directional DC/DC converters for plug-in hybrid electric vehicle (PHEV) applications," Applied Power Electronics Conference and Exposition, 2008. APEC 2008. Twenty-Third Annual IEEE, vol., no., pp.784,789, 24-28 Feb. 2008, doi: 10.1109/APEC.2008.4522810

[11]. Dawei He; Ntsama, P.; Jinchi Han; Habetler, T.G., "A novel isolated bidirectional DC-DC converter for ultra-capacitor application in hybrid and electric vehicles," IECON 2012 - 38th Annual Conference on IEEE Industrial Electronics Society, vol., no., pp.2872,2876, 25-28 Oct. 2012, doi: 10.1109/IECON.2012.6389439

[12]. M.K. Kazimierczuk, D.Q. Vuong, B.T. Nguyen, J.A. Weimer, 'Topologies of bidirectional PWM dc-dc power converters', IEEE 1993 National Aerospace and Electronics Conference (NAECON'93), 24-28 May 1993, pp. 435 - 441.

[13]. Huang-Jen Chiu; Li-Wei Lin, "A bidirectional DC-DC converter for fuel cell electric vehicle driving system", Power Electronics, IEEE Transactions on, vol.21, no.4, pp.950,958, July 2006, doi: 10.1109/TPEL.2006.876863

[14]. Tsai-Fu Wu; Yung-Chu Chen; Jeng-Gung Yang; Chia-Ling Kuo, "Isolated Bidirectional Full-Bridge DC-DC Converter With a Flyback Snubber," Power Electronics, IEEE Transactions on , vol.25, no.7, pp.1915,1922, July 2010, doi: 10.1109/TPEL.2010.2043542

[15]. Tsai-Fu Wu; Jeng-Gung Yang; Chia-Ling Kuo; Kun-Han Sun; Yu-Kai Chen, "Comparison of bi-directional isolated full-bridge converters with combinations of active and passive snubbers," Energy Conversion Congress and Exposition (ECCE), 2011 IEEE, vol., no., pp.127,133, 17-22 Sept. 2011, doi: 10.1109/ECCE.2011.6063759

[16]. Hui Li; Fang Zheng Peng; Lawler, J.S., "A natural ZVS mediumpower bidirectional DC-DC converter with minimum number of devices," Industry Applications, IEEE Transactions on , vol.39, no.2, pp.525,535, Mar/Apr 2003, doi: 10.1109/TIA.2003.808965

[17]. Peng, F.Z.; Hui Li; Gui-Jia Su; Lawler, J.S., "A new ZVS bidirectional DC-DC converter for fuel cell and battery application," Power Electronics, IEEE Transactions on , vol.19, no.1, pp.54,65, Jan. 2004, doi: 10.1109/TPEL.2003.820550

[18]. M. Jain, M. Daniele, P.K. Jain, "A bidirectional DC-DC converter topology for low power application" IEEE Transactions on Power Electronics, Vol. 15, n. 4, July 2000, pp. 595 - 606.

[19]. F. Giulii Capponi, M. Cacciato, "Using Super Capacitors in Combination with Bi-Directional DC/DC Converters for Active Load Management in Residential Fuel Cell Applications", 1st European Symposium on Supercapacitors (ESSCAP'04), Belfort (France), 4-5 November 2004.

[20]. Cacciato, M.; Caricchi, F.; Giuhlii, F.; Santini, E., "A critical evaluation and design of bi-directional DC/DC converters for super-capacitors interfacing in fuel cell applications,"Industry Applications Conference, 2004. 39th IAS Annual Meeting. Conference Record of the 2004 IEEE, vol.2, no., pp.1127,1133 vol.2, 3-7 Oct. 2004, doi: 10.1109/IAS.2004.1348554

[21]. F. Giulii Capponi; Santoro, P.; Crescenzi, E., "HBCS Converter: A Bidirectional DC/DC Converter for Optimal Power Flow Regulation in Supercapacitor Applications," Industry Applications Conference, 2007. 42nd IAS Annual Meeting. Conference Record of the 2007 IEEE, vol., no., pp.2009,2015, 23-27 Sept. 2007. doi: 10.1109/07IAS.2007.304 